\title{
Preparation of Curcumin Nanosuspension with Gum Arabic as a Natural Stabilizer: Process Optimization and Product Characterization
}

\author{
Bao Hoang Duong ${ }^{1,2}$, Hoai Nam Truong 1,2, Quynh Anh Phan Nguyen 1,2, \\ Thuong Nhan Nguyen Phu ${ }^{3,4, *}$ and Le Thi Hong Nhan ${ }^{1,2, *}$ \\ 1 Department of Chemical Engineering, Ho Chi Minh City University of Technology (HCMUT), 268 Ly Thuong \\ Kiet Street, District 10, Ho Chi Minh City 700000, Vietnam; duongbaohoang1996@gmail.com (B.H.D.); \\ hoainamtrg@gmail.com (H.N.T.); pnqanh@hcmut.edu.vn (Q.A.P.N.) \\ 2 Vietnam National University Ho Chi Minh City, Linh Trung Ward, Thu Duc District, \\ Ho Chi Minh City 700000, Vietnam \\ 3 NTT Hi-Tech Institute, Nguyen Tat Thanh University, Ho Chi Minh City 700000, Vietnam \\ 4 Center of Excellence for Biochemistry and Natural Products, Nguyen Tat Thanh University, \\ Ho Chi Minh City 700000, Vietnam \\ * Correspondence: nptnhan@ntt.edu.vn (T.N.N.P.); 1thnhan@hcmut.edu.vn (L.T.H.N.)
}

Received: 30 June 2020; Accepted: 15 July 2020; Published: 12 August 2020

check for updates

\begin{abstract}
Low aqueous solubility and poor bioavailability of curcumin have limited its application in various fields. One approach to address this issue is to formulate a nanosuspension that incorporates curcumin, which has been previously shown to exhibit remarkably improved solubility in comparison with that of a bare compound. In this study, the preparation process of curcumin nanosuspension was optimized with a median particle size as the outcome. Gum arabic was used as a natural polymeric surfactant and the suspension was formulated using high speed homogenization. Optimization results, realized via a response surface methodology, showed that a minimum median particle size $(8.524 \mu \mathrm{m})$ could be attained under the following conditions: curcumin:gum arabic ratio of 1:6 g/g; homogenization speed of $8300 \mathrm{rpm}$ and homogenization time of $40 \mathrm{~min}$. Under these conditions, the particle size of obtained suspension was shown to be consistent for around seven days without major aggregation. The homogenization process could be scaled up to five times in terms of suspension volume. TEM also showed that curcumin nanoparticles had a nearly spherical shape and homogeneous structure with a size range of $40-80 \mathrm{~nm}$.
\end{abstract}

Keywords: curcumin; nanosuspension; gum arabic; high speed homogenization; response surface methodology

\section{Introduction}

Curcumin, a constituent derived from the rhizome of turmeric (Curcuma longa), has been a promising lead for drug development due to a wide spectrum of biological activities [1]. Clinical trials have suggested that curcumin might hold potential in the treatment of several diseases and cancers, such as gastric, colorectal, pancreatic and hepatic cancers [2]. Furthermore, inexpensive and effortless production of curcumin also greatly enhances the feasibility of using the compound in large-scale manufacturing in pharmaceutical industries. This is, unfortunately, bottlenecked by poor water solubility and limited bioavailability and absorption in oral administration of curcumin.

Previous attempts aiming at improving the solubility and bioavailability of curcumin have been carried out with different strategies. Basniwal et al. (2014) showed that curcumin nanoparticles, prepared using wet milling with dichloromethane solvent, exhibited improved solubility in water 
and thus better antiproliferative effects on several human cancer cell lines [3]. In other lines of study, curcumin could be either encapsulated in different polymer nanoparticles to form composite delivery systems with sustained release, or spray dried using natural wall materials to form microcapsules with prolonged core retention [4], hence enhancing bioavailability. Approaches that involve formulation of a curcumin nanosuspension have been intensively studied [5-7]. Most notably, Gao et al. (2011) evaluated a number of nanosuspension-forming methods and stabilizer systems and suggested that the use of high-speed homogenization, in combination with soya lecithin/sodium deoxycholate surfactant, was most facile for the preparation of a curcumin nanosuspension. The obtained nanosuspension also showed remarkably higher solubility and cytotoxicity against Hela and MCF-7 cell lines in vitro in comparison with those of pristine curcumin. Those approaches were also further refined in other studies by co-loading curcumin with other drugs, such as docetaxel [8] and doxorubicin [9], to confer the resulting nanosuspension with more potent inhibitory properties against cancer cells.

The capability of nanosuspension to incorporate drugs with low aqueous solubility and commercial availability of nanosuspension products in the pharmaceutical market have driven the effort in enhancing applicability of curcumin into this formulation technique. However, reported attempts in formulation of the curcumin nanosuspensions suffer from certain shortcomings that limit their real-scale applications, such as difficulty in acquisition of raw materials with required quantity or inadequate process optimization with respect to particle size [10,11]. In this study, we explored the possibility and the process of formulating a curcumin nanosuspension system using gum arabic (GA), a natural biopolymer, as the surfactant. The particle size of the curcumin in the suspension was optimized using response surface methodology (RSM) and various process parameters were considered including curcumin to GA ratio, homogenization speed and time, and curcumin concentration. In addition, a stability test of the obtained nanosuspension was carried out under extended preservation. The results are expected to justify the nanosuspension approach in extending curcumin application in pharmaceutical, food and cosmetic fields.

\section{Materials and Methods}

\subsection{Preparation of Curcumin Nanosuspension}

Curcumin nanosuspension was prepared by homogenizing two following mixtures using a high-speed homogenizer (FJ300-SH High Speed Dispersion Machine, MXBAOHENG). The first mixture was prepared by dissolving an appropriate amount of curcumin powder (95\% purity, Apollo Ingredients Ltd., India) into $5 \mathrm{~mL}$ of $98 \%$ ethanol (Nguyen Quan Ltd., Vietnam). The second mixture contained gum arabic (Willy Benecke $\mathrm{GmbH}$, Hamburg, Germany) and $100 \mathrm{~mL}$ of distilled water at an appropriate ratio. The two mixtures were then homogenized at a predetermined speed and duration. In the very first investigation, the curcumin to gum arabic ratio was allowed to vary from 1:1 to 1:15 and other conditions were kept at constant levels as follows: homogenization speed of $7000 \mathrm{rpm}$, time of $30 \mathrm{~min}$ and curcumin concentration of $0.5 \mathrm{~g} / \mathrm{L}$.

\subsection{Size Measurement of Curcumin Particle in the Nanosuspension}

The particle size distribution and median diameter of the dispersion system were determined by the laser diffraction spectrometry (LDS) method using Horiba LA-950V2 instrument. All analyses were performed in auto-measuring mode at $25{ }^{\circ} \mathrm{C}$ and the results were presented as the average value of duplicate samplings and measurement for each formulation.

\subsection{Response Surface Methodology Optimization of the Nanosuspension Preparation Process}

Based on single-factor investigation results, we employed an RSM procedure, in combination with central composite design, to further optimize preparation parameters with respect to minimal median particle size. The model for RSM could be described as follows 


$$
\mathrm{Y}=\mathrm{B}_{0}+\sum \mathrm{B}_{\mathrm{i}} \mathrm{X}_{\mathrm{i}}+\sum \mathrm{B}_{\mathrm{ii}} \mathrm{X}_{\mathrm{i}}^{2}+\sum \mathrm{B}_{\mathrm{ij}} \mathrm{X}_{\mathrm{i}} \mathrm{X}_{\mathrm{j}}
$$

In which $B_{0}$ is the response factor at the center, $B_{i}$ is the first-order response factor, $B_{i i}$ is the second-level response factor, $B_{i j}$ is the double-interactive response factor, $X_{i}$ is the encoded variable of the real variables and $Y$ is the predicted response. Three factors, ratio of curcumin and gum arabic, homogenization speed and homogenization time, were incorporated into the model and the median particle size was taken as the output response.

Firstly, central composite experiment design was commenced to calculate the lower, center and upper limit for each variable (Table 1) and to generate 16 parameter combinations, which would be actually attempted to generate the response data for estimation of model coefficients. Then, after the model coefficients had been estimated, the independent variables were statistically evaluated via Fisher standard of independent variables with $p$-value $<0.05$ and the model was assessed via coefficient of determination, $\mathrm{R}^{2}$, which implies a greater fit between model and experimental values if its value approximates 1 . Lastly, the selected model was then optimized to calculate the optimal conditions that give minimal median particle size. The optimal set of parameters were then experimented in a triplicate run to confirm the results. Acceptable difference between predicted and experimental response was within 5\%. The whole RSM optimization procedure was carried out in JMP PRO 13.0 software.

Table 1. Examined parameters for response surface methodology (RSM) optimization and their bound values.

\begin{tabular}{cccc}
\hline \multirow{2}{*}{ Value } & \multicolumn{3}{c}{ Factors } \\
\cline { 2 - 4 } & Homogenization Time (D) (min) & Ratio (R) (g/g) & Speed (S) (rpm) \\
\hline Lower limit (-1) & 15 & 5 & 3000 \\
Center point (0) & 30 & 10 & 7000 \\
Upper limit (+1) & 45 & 15 & 11,000 \\
Encoding variables $(\mathrm{Xi})$ & $\mathrm{X}_{1}=\frac{\mathrm{D}-30}{15}$ & $\mathrm{X}_{2}=\frac{\mathrm{R}-10}{5}$ & $\mathrm{X}_{3}=\frac{\mathrm{S}-7000}{4000}$ \\
\hline
\end{tabular}

\subsection{Morphological Evaluation of the Nanosuspension Product}

The particle size and structure of the dispersion system were determined by the transmission electron microscopy (TEM) method. Sample analysis was carried out on a JEM1010-JEOL instrument at the Key Laboratory of Polymer and Composite Materials in C6 Building, Ho Chi Minh University of Technology-VNU-HCM.

\subsection{Stability Test}

The final suspension product was stored for 14 days. Particle size measurements were performed at the 1 st, 7 th and 14 th days.

\subsection{Scalability Test}

The optimized preparation process was then scaled up to different suspension volumes $(200,300$ and $500 \mathrm{~mL}$ ) and the products of the scaled process were measured for particle sizes. Multiple cylinder cups of different sizes were used appropriately to contain the suspension.

\section{Results}

\subsection{Single Factor Investigations}

In the first single-factor investigation, the selected curcumin:GA ratios were 1:1, 1:5, 1:10 and 1:15. Formulation of the mixture at the ratio of 1:1 resulted in a system in which curcumin was not well dispersed and experienced rapid phase separation [12]. Therefore, the three other ratios were used and the results are illustrated in Figure 1. 


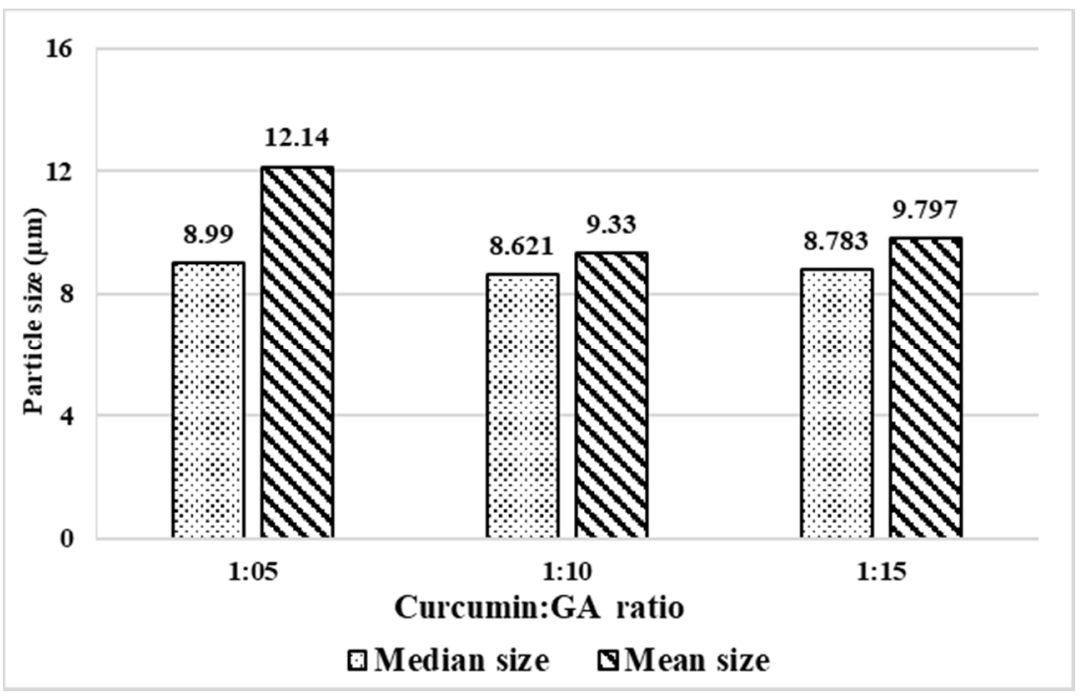

Figure 1. Effect of different curcumin:gum Arabic (GA) ratios on particle size of suspensions.

Visually, increasing thickness and viscosity was observed in the suspension as a higher amount of gum arabic was added, which was possibly due to the high concentration of the swelling polymer in the system [13]. In addition, the yellow color of the suspension became darker as the ratio changed from 1:5 to 1:10. Regarding particle size, it was observed that excessive addition of gum arabic seemed to produce suspension with lower median particle size. However, the difference between the median size observed at 1:5 ratio and at 1:15 ratio was marginal. This was contrasted by the pronounced reduction in mean size obtained when increasing the GA content. To be specific, the mean size showed dramatic decrease from $12.14 \mu \mathrm{m}$ to $9.33 \mu \mathrm{m}$ when changing the ratio from $1: 5$ to $1: 10 \mathrm{~g} / \mathrm{g}$. The consistency between mean and median particle size indicated that the suspension particles were uniform and that no aggregation took place. At the ratio of 1:15, calculated particle size was larger and a slight discrepancy between mean and median could be observed. This could be explained by the formation of polymer aggregates [14]. Therefore, the ratio of 1:10 was selected for subsequent investigations.

Figure 2 illustrates variations in particle size obtained at different homogenizing speeds $(3000$, 5000, 7000, 9000 and 11,000 rpm). At first glance, samples prepared at homogenizing speeds ranging from 3000 to $9000 \mathrm{rpm}$ showed no clear differences in terms of color characteristics. At 11,000 rpm, the color of the homogenized product was darker, possibly due to denaturation of curcumin and polymer when being exposed to high levels of energy [15].

For particle size, increasing the homogenizing speed caused the particle size to diminish. The median size was reduced from 8.64 to $7.46 \mu \mathrm{m}$ in the case of increasing the speed from 3000 to $11,000 \mathrm{rpm}$. However, the progressive reduction is not clear, except at $11 \mathrm{rpm}$ at which point the particle size was remarkably smaller. The explanation could be due to the increased energy density, which is caused by high rotating capacity that directs sufficient energy to the system and further breaks down curcumin particles [16]. In addition, all samples exhibited excellent size distribution, as evidenced by minor differences between median and mean sizes. Considering operational instability of the homogenization instrument and increased cost at 9000 and 11,000 rpm, $7000 \mathrm{rpm}$ was selected as the optimal homogenizing speed for subsequent investigations.

The homogenization time was studied at four different points including 15, 30, 45 and 75 min and the results are shown in Figure 3.

Among four samples prepared at different homogenization durations, the sample prepared in $45 \mathrm{~min}$ and that at $75 \mathrm{~min}$ showed a noticeably darker yellow color in comparison with those of the other two samples. It is possible that homogenization under an extended period has led to an elevated temperature in the system, in turn causing degradation of curcumin and the polymer [17]. In terms of particle size, the suspension obtained under $15 \mathrm{~min}$ of homogenization showed the largest particle 
size with the difference between mean and median being the most striking, which is indicative of low uniformity of the particles in the nanosuspension. The most favorable particle size measurements (median of 8.31 and mean of $8.98 \mu \mathrm{m}$ ) were achieved at $30 \mathrm{~min}$ of homogenization time. Prolonging the time past this point seemed to result in suspensions with larger particle sizes and worse homogeneity, possibly due to the formation of clumped particles [18].

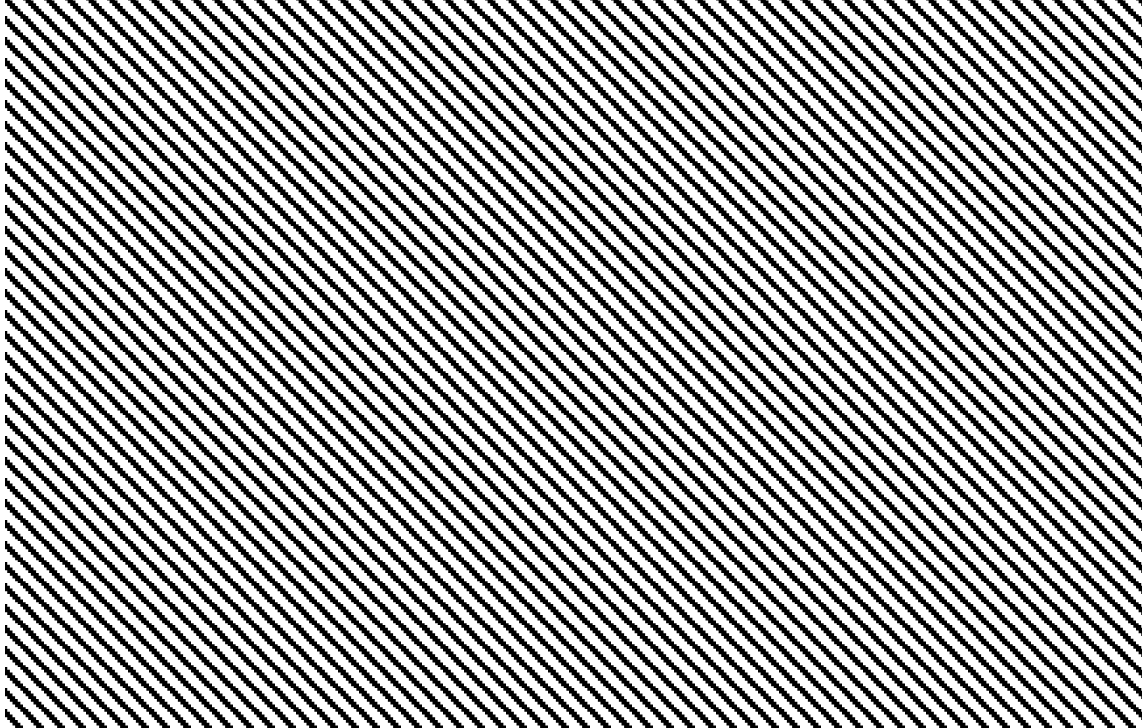

Figure 2. Effect of different homogenization speeds on particle size of suspensions.

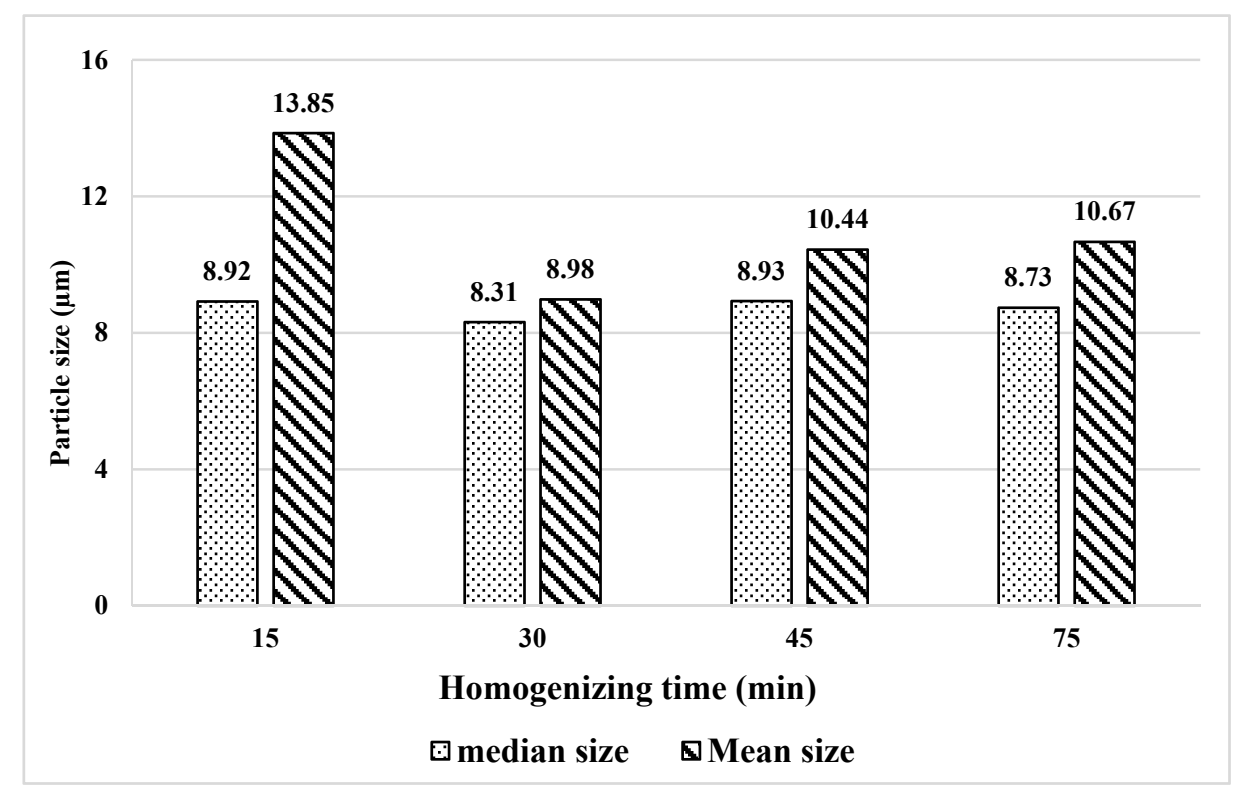

Figure 3. Effect of different homogenization durations on particle size of suspensions.

Figure 4 represents variations of particle size with respect to different curcumin concentrations. Sensorial examination of the samples revealed that increasing the curcumin concentration induced darker color and greatly affected viscosity of the suspension. Due to increased viscosity at high curcumin concentration, operational stability of the homogenizer was impaired, resulting in a product with unfavorable particle size [19]. Indeed, the median particle size rose from 8.31 to $9.87 \mu \mathrm{m}$ when curcumin concentration was increased from 0.5 to $5 \mathrm{~g} / \mathrm{L}$. Moreover, at higher curcumin concentrations, mean particle sizes were far greater than median values, suggesting the right-skewness of the size 
distribution and the prevalence of larger particles. Therefore, optimal curcumin concentration was selected as $0.5 \mathrm{~g} / \mathrm{L}$.

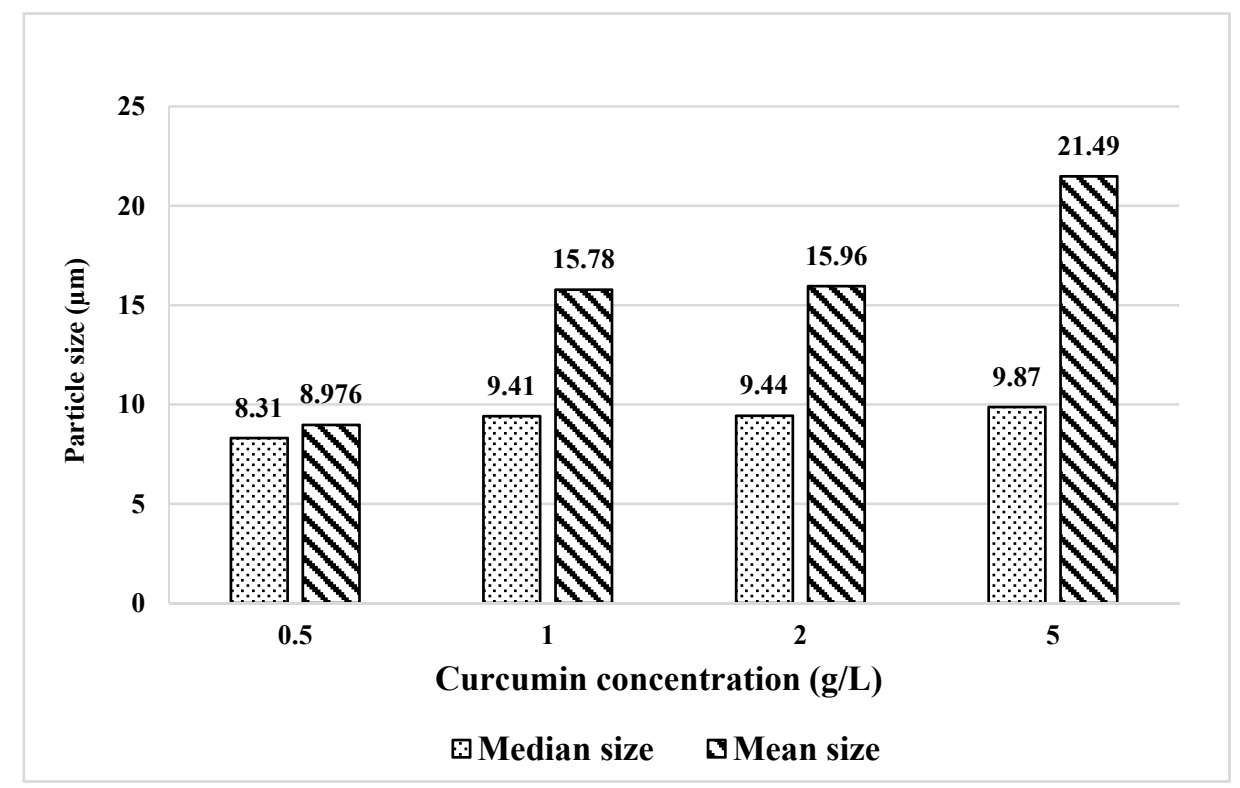

Figure 4. Effect of different curcumin concentrations on particle size of suspensions.

\subsection{RSM Optimization Results}

Based on the determined optimal set of parameters, the central composite design was employed to produce parameters for further experimental runs. The generated parameters and their corresponding experimental responses are shown in Table 2.

Table 2. Experimental parameters and responses for RSM optimization.

\begin{tabular}{ccccc}
\hline \multirow{2}{*}{ Experiment No. } & \multicolumn{3}{c}{ Independent Variables } & Experimental Response \\
\cline { 2 - 5 } & $\mathbf{X}_{\mathbf{1}} \mathbf{( \mathbf { m i n } )}$ & $\mathbf{X}_{\mathbf{2}} \mathbf{( g / g )}$ & $\mathbf{X}_{\mathbf{3}} \mathbf{( \mathbf { r p m } )}$ & $\mathbf{Y}(\boldsymbol{\mu \mathbf { m } )}$ \\
\hline 1 & $-1(15)$ & $-1(5)$ & $-1(3000)$ & 8.827 \\
2 & $-1(15)$ & $-1(5)$ & $+1(11,000)$ & 7.782 \\
3 & $-1(15)$ & $0(10)$ & $0(7000)$ & 8.272 \\
4 & $-1(15)$ & $+1(15)$ & $-1(3000)$ & 10.571 \\
5 & $-1(15)$ & $+1(15)$ & $+1(11,000)$ & 8.383 \\
6 & $0(30)$ & $-1(5)$ & $0(7000)$ & 7.992 \\
7 & $0(30)$ & $0(10)$ & $-1(3000)$ & 9.718 \\
8 & $0(30)$ & $0(10)$ & $0(7000)$ & 8.625 \\
9 & $0(30)$ & $0(10)$ & $0(7000)$ & 8.595 \\
10 & $0(30)$ & $0(10)$ & $+1(11,000)$ & 8.457 \\
11 & $0(30)$ & $+1(15)$ & $0(7000)$ & 9.197 \\
12 & $+1(45)$ & $-1(5)$ & $-1(3000)$ & 9.346 \\
13 & $+1(45)$ & $-1(5)$ & $+1(11,000)$ & 8.632 \\
14 & $+1(45)$ & $0(10)$ & $0(7000)$ & 8.242 \\
15 & $+1(45)$ & $+1(15)$ & $-1(3000)$ & 10.186 \\
16 & $+1(45)$ & $+1(15)$ & $+1(11,000)$ & 8.497 \\
\hline
\end{tabular}

After fitting the model, the estimation results for the standard model are shown as in Table 3. 
Table 3. Coefficients of the standard regression model.

\begin{tabular}{|c|c|c|c|c|}
\hline Independent Variable & Coeff. & Std Error & t Ratio & Prob $>|t|$ \\
\hline Intercept & 8.525 & 0.076 & 112.210 & $<0.0001$ \\
\hline Homogenization time & 0.107 & 0.051 & 2.100 & 0.080 \\
\hline Ratio & 0.426 & 0.051 & 8.390 & 0.000 \\
\hline Speed & -0.690 & 0.051 & -13.590 & $<0.0001$ \\
\hline Homogenization time $\times$ Ratio & -0.205 & 0.057 & -3.610 & 0.011 \\
\hline Homogenization time $\times$ Speed & 0.104 & 0.057 & 1.830 & 0.117 \\
\hline Ratio $\times$ Speed & -0.265 & 0.057 & -4.670 & 0.003 \\
\hline Homogenization time $^{2}$ & -0.225 & 0.099 & -2.280 & 0.063 \\
\hline Ratio $^{2}$ & 0.112 & 0.099 & 1.140 & 0.299 \\
\hline Speed $^{2}$ & 0.605 & 0.099 & 6.130 & 0.001 \\
\hline
\end{tabular}

To illustrate interaction effects between variables on the response, response surfaces were plotted in which particle size was taken as the vertical axis and two variables as horizontal axes (Figure 5). In each plot, the absent variable was kept at its central value. It is shown that the effects of both speed and ratio on the particle size are similar where increased speed or ratio leads to smaller particle size. This relationship, however, only holds to a certain parameter level after which a reverse trend is shown. On the other hand, the interaction between time and ratio showed a different pattern where increasing duration seems to lead to reduced particle size and the optimal pair of conditions may be situated outside of the experiment range, given that the third factor (speed) is maintained at the central point. Lastly, the surface plot illustrating the interaction of duration and homogenization speed indicates that minimum particle size could be achieved within the speed range of 7000-10,000 and that very low or extreme homogenization speed might produce particles with larger size.

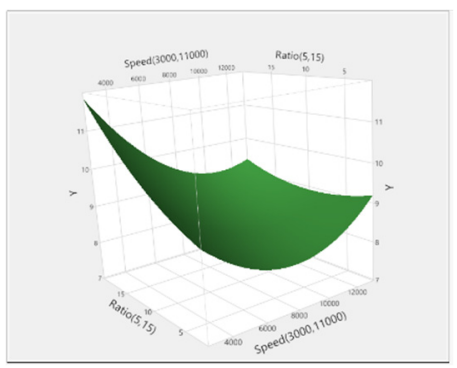

Speed $\times$ Ratio

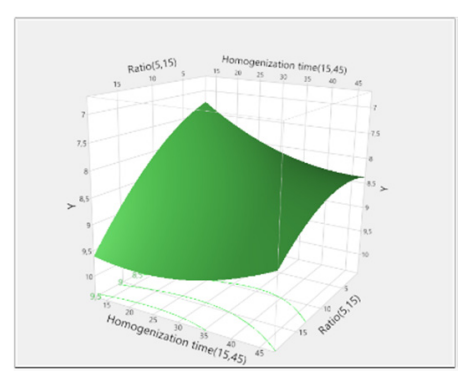

Homogenization time $\times$ Ratio

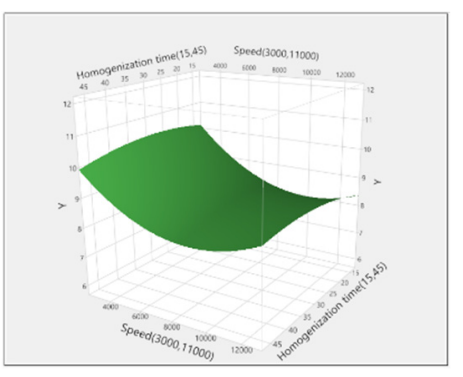

Homogenization time $\times$ Speed

Figure 5. Interaction effects of pairs of factors on the response.

Figure 6 plots data points formed by actual and predicted responses. It was shown that distribution of the data is in close proximity to the 45-degree line, suggesting that experimental results agreed well with predicted results. In addition, the calculated determination coefficient $\left(R^{2}=0.98\right)$ and RSME value of 0.1605 indicate a good fitting quality between experiment data and the established model.

Effects of individual parameters on the median particle size are shown in Figure 7. In each plot, one variable is allowed to vary, and two missing variables are kept at their central points. Apparently, the median particle size is most responsive to changes in homogenization speed, as shown by the sloppiness of the curves, and lowering the speed to below $7000 \mathrm{rpm}$ caused the particle size to increase greatly. On the other hand, the curcumin:GA ratio is positively correlated to the response whereas the homogenization time appears to be irrelevant to median particle size. 


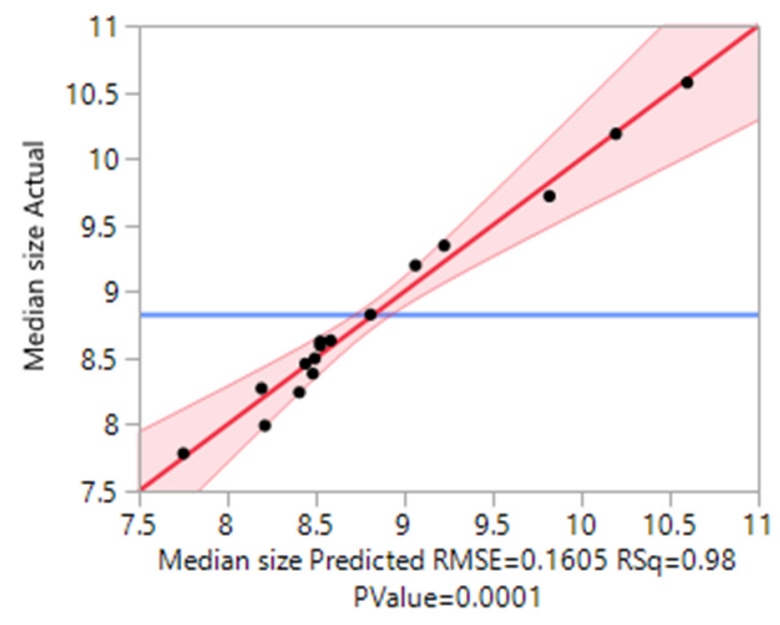

Figure 6. Predicted versus experimental responses.

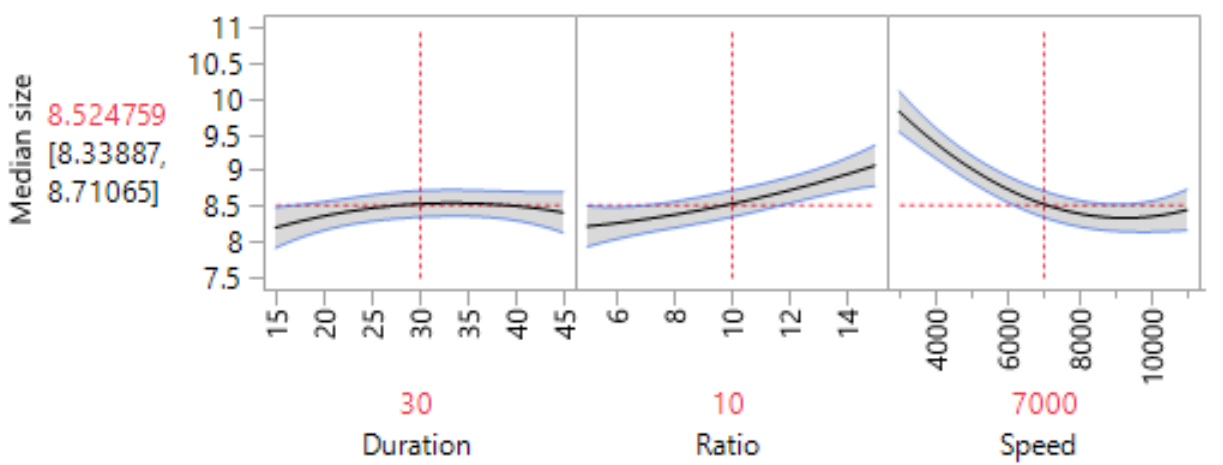

Figure 7. Effects of individual parameters on the response.

After reducing the model by removing variables whose $p$-values are higher than 0.05 , the final model is described as follows

$$
Y=0.425 X_{2}-0.689 X_{3}-0.205 X_{1} X_{2}-0.264 X_{2} X_{3}+0.605 X_{3}^{2}+8.524
$$

Inferring from the final model, the median particle size seemed to be individually affected by the curcumin:GA ratio $\left(X_{2}\right)$ and homogenization speed $\left(X_{3}\right)$. Homogenization time $\left(X_{1}\right)$, although being directly relevant to the response, mediates the influence of ratio. In addition, homogenization speed is the only variable that affects the response in a U-shaped manner.

Optimization of the function with respect to minimal response yielded following optimal conditions: Curcumin to GA ratio of 1:5.635 g/g, homogenization time of $40.618 \mathrm{~min}$ and homogenization speed of $8272.49 \mathrm{rpm}$. These conditions corresponded to the minimum median particle size of $8.203 \mu \mathrm{m}$.

Lastly, an actual experiment run was performed to validate the optimal results. We slightly adjusted the parameters to ease experimental operation to as follows: curcumin to GA ratio of 1:6 g/g, homogenization time of $40 \mathrm{~min}$ and homogenization speed of $8300 \mathrm{rpm}$. The first, second and third run resulted in the median particle size of $8.887,8.507$ and $8.177 \mu \mathrm{m}$, respectively, which are averaged to $8.524 \mu \mathrm{m}$. Compared with the predicted optimal response, the calculated deviation was sufficiently low, at $3.91 \%$, which indicates that the established model is adequate in predicting the outcome of the experiment.

\subsection{Scalability Test}

Experiments were carried out at the optimized conditions, but with greater suspension volumes, to determine whether scaling up the fabrication process might impair the product quality. To facilitate 
larger volume of suspensions, plastic cylinder cups with larger diameters were used [20]. The details are shown in Table 4.

Table 4. Suspension volume, diameters of containers and obtained particle size in the scalability test.

\begin{tabular}{ccc}
\hline Suspension Volume & Diameter of the Container $(\mathbf{c m})$ & Median Particle Size $(\boldsymbol{\mu m})$ \\
\hline$\times 1(100 \mathrm{~mL})$ & 6.1 & 8.5242 \\
\hline$\times 2(200 \mathrm{~mL})$ & 7.9 & 8.4407 \\
\hline$\times 3(300 \mathrm{~mL})$ & 8.9 & 8.3408 \\
\hline$\times 5(500 \mathrm{~mL})$ & 12.4 & 8.5701 \\
\hline
\end{tabular}

There was no significant difference in the median particle size of the suspension when conducting tests at different volumes. When increasing the scale of the experiment to $\times 5$, the uniformity of the system was slightly reduced due to the emergence of some particles that were in the size range separated from the distribution bell to the right, at around $100 \mu \mathrm{m}$. On the other hand, median size of the suspensions remained relatively stable regardless of the container used and suspension volume. This indicates that the calculated optimal parameters could be employed with high flexibility and good compatibility in increasing production scale.

\subsection{Characterization and Stability Test of the Nanosuspension Product}

Figure 8 illustrates the nanosuspension prepared at optimized conditions. In general, the texture of the nanosuspension was uniform and the yellow color was bright and translucent. The system achieved a median particle size of $8.524 \mu \mathrm{m}$ (Figure 9) with a symmetrical bell-shaped distribution that has no outliers, showing that the system had an excellent size distribution.

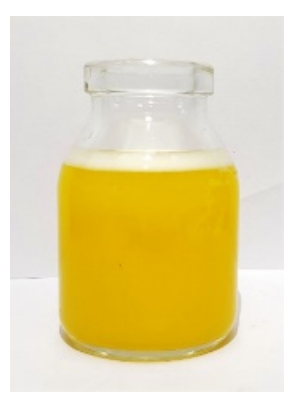

$\begin{array}{ll}\text { Ratio curcumin: GA }(\mathrm{g} / \mathrm{g}) & 1: 6 \\ \text { Concentration }(\mathrm{g} / \mathrm{L}) & 0.5 \\ \text { Color }(\mathrm{L}, \mathrm{C}, \mathrm{h}) & \begin{array}{l}\text { Bright yellow } \\ 37.34,24.19,90.95\end{array} \\ \text { Average size by LDS }(\mu \mathrm{m}) & 8.524 \\ & \\ \text { Average size by TEM }(\mathrm{nm}) & 40-80\end{array}$

Figure 8. Curcumin nanosuspension with gum arabic as the stabilizer.

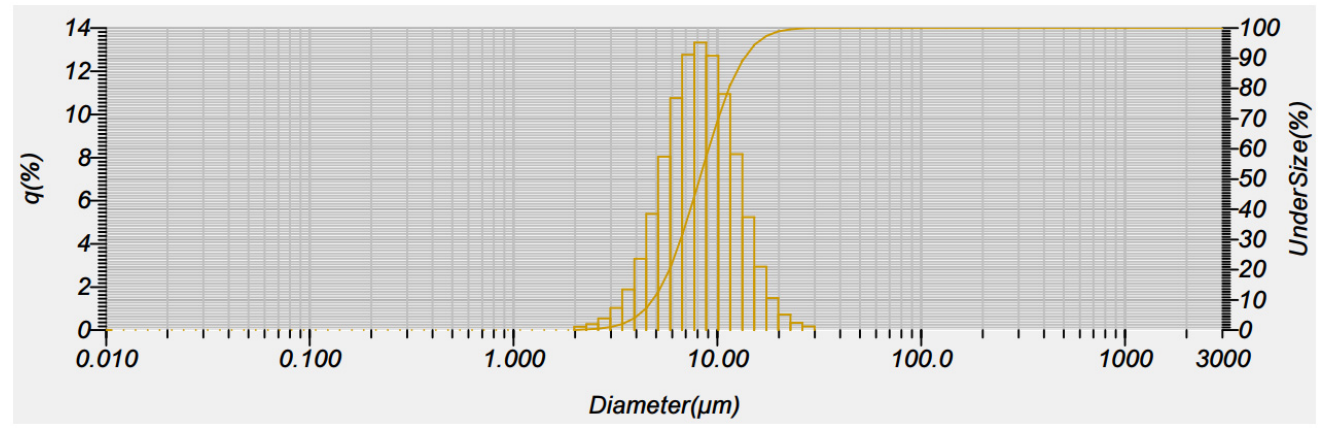

Figure 9. Size distribution of curcumin nanosuspension analyzed by laser diffraction spectrometry (LDS).

Figure 10 shows the shape and size of nanoparticles determined by TEM method. Curcumin nanoparticles have been determined to have a nearly spherical shape, homogeneous particle structure and relatively uniform size distribution in the range of 40-80 $\mathrm{nm}$. However, the particles had a 
slight clumping phenomenon, possibly due to the high concentration of GA in nanosuspension [21]. The particle diameter determined by TEM was much smaller than the result from the LDS analysis because the LDS method measures both the particles with outer solvate layer and clumped particles.
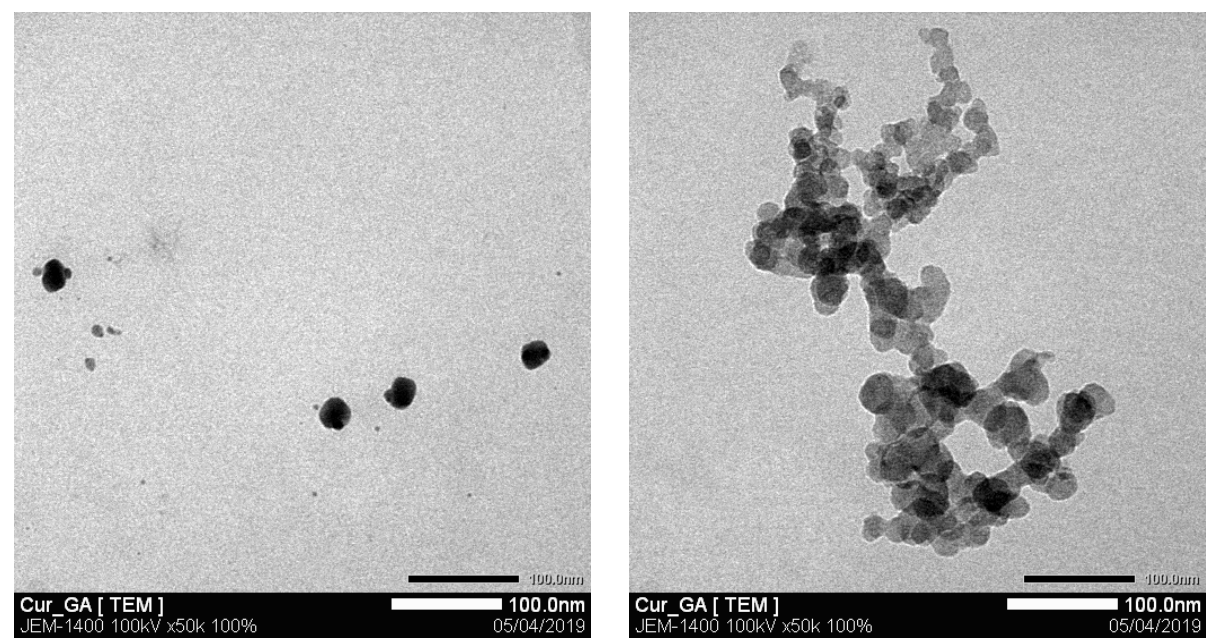

Figure 10. Morphology, structure and size of the curcumin nanosuspension analyzed by TEM.

The nanosuspension was stored for two weeks at room temperature and its particle size was measured afterwards. The results are shown in Figure 11. After two weeks, the median size of the system showed no significant changes. On the contrary, mean size of particles seemed to gradually increase after each week, from 9.802 to $15.600 \mu \mathrm{m}$ over the whole course of the examined period. The reason might be due to aggregation of the particles [22,23]. The large difference between the median and mean sizes at the 14th day indicated that the system was not homogenous. Therefore, to maintain the consistency and cell penetrating ability of the product, the prepared suspension should be used before one week. Otherwise, other preservation methods should be applied to improve its stability and shelf-life.

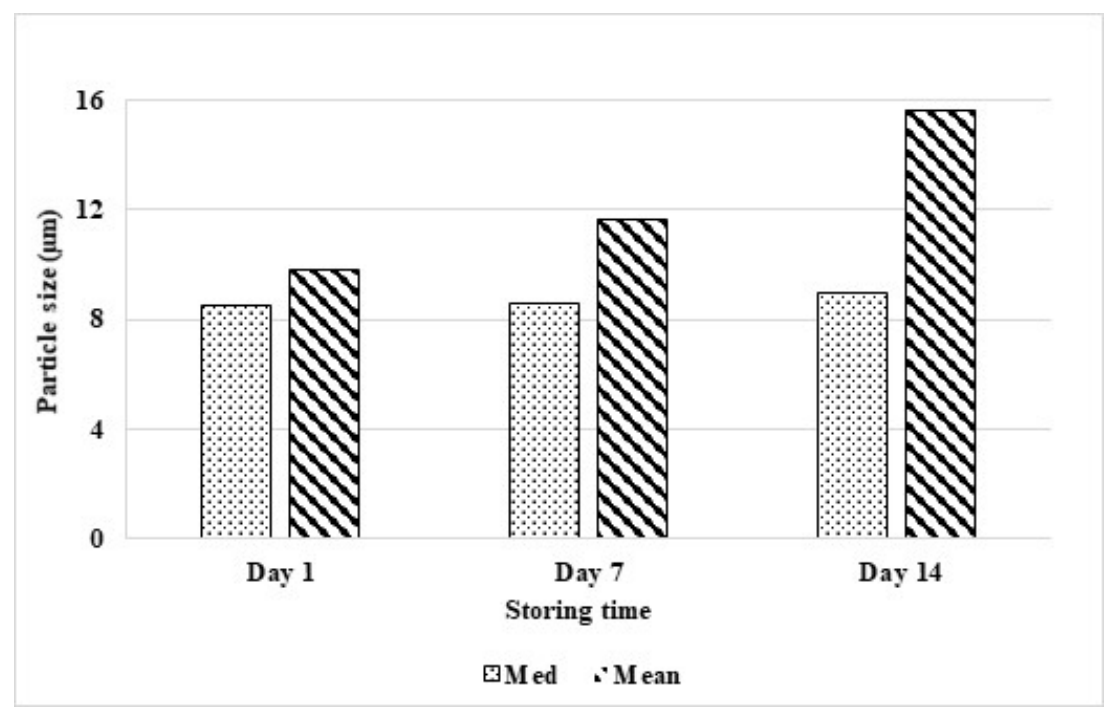

Figure 11. Stability of the nanosuspension for two weeks.

\section{Conclusions}

A curcumin nanosuspension was prepared with gum arabic as a stabilizer by using high-speed homogenization. Optimization of the preparation process was carried out using response surface 
methodology with respect to the minimal median particle size of curcumin. Three examined experimental parameters consisted of curcumin:GA ratio, homogenization time and homogenization speed. After validating the model and confirming the optimal response, following optimized conditions were obtained: curcumin:GA ratio of 1:6 g/g; homogenization speed of $8300 \mathrm{rpm}$ and homogenization time of $40 \mathrm{~min}$, which corresponds to the particle size of $8.524 \mu \mathrm{m}$. A scalability test revealed that the process could be performed at a suspension volume that is five-fold higher than the original volume without significant compromise in visual characteristics and product uniformity. TEM also showed that curcumin nanoparticles had a nearly spherical shape and homogeneous particle structure with the size range of $40-80 \mathrm{~nm}$. The obtained suspension could be used within seven days after fabrication without loss of particle size consistency. Further studies should extend the investigation in terms of zeta potential measurements and assaying biological activities of the product.

Author Contributions: Investigation, B.H.D., H.N.T., Q.A.P.N. and T.N.N.P.; supervision, L.T.H.N.; writing一original draft, B.H.D. All authors have read and agreed to the published version of the manuscript.

Funding: This research received no external funding.

Conflicts of Interest: The authors declare no conflicts of interest.

\section{References}

1. Aggarwal, B.B.; Harikumar, K.B. Potential therapeutic effects of curcumin, the anti-inflammatory agent, against neurodegenerative, cardiovascular, pulmonary, metabolic, autoimmune and neoplastic diseases. Int. J. Biochem. Cell Biol. 2009, 41, 40-59. [CrossRef]

2. Giordano, A.; Tommonaro, G. Curcumin and Cancer. Nutrients 2019, 11, 2376. [CrossRef]

3. Basniwal, R.K.; Khosla, R.; Jain, N. Improving the Anticancer Activity of Curcumin Using Nanocurcumin Dispersion in Water. Nutr. Cancer 2014, 66, 1015-1022. [CrossRef] [PubMed]

4. Cano-Higuita, D.M.; Malacrida, C.R.; Telis, V.R.N. Stability of Curcumin Microencapsulated by Spray and Freeze Drying in Binary and Ternary Matrices of Maltodextrin, Gum Arabic and Modified Starch. J. Food Process. Preserv. 2015, 39, 2049-2060. [CrossRef]

5. Jusnita, N.; Haditjaroko, L.; Yusron, M.; Noor, E. Production of Nanocurcumin from Curcuma Xanthorriza Roxb. by Homogenization. J. Biol. Agric. Healthc. 2014, 4, 79. Available online: https://www.iiste.org/ Journals/index.php/JBAH/article/view/14485 (accessed on 1 June 2020).

6. Gao, Y.; Li, Z.; Sun, M.; Li, H.; Guo, C.; Cui, J.; Li, A.; Cao, F.; Xi, Y.; Lou, H.; et al. Preparation, characterization, pharmacokinetics, and tissue distribution of curcumin nanosuspension with TPGS as stabilizer. Drug Dev. Ind. Pharm. 2010, 36, 1225-1234. [CrossRef]

7. Aditya, N.P.; Yang, H.; Kim, S.; Ko, S. Fabrication of amorphous curcumin nanosuspensions using $\beta$-lactoglobulin to enhance solubility, stability, and bioavailability. Colloids Surf. B 2015, 127, $114-121$. [CrossRef] [PubMed]

8. Sahu, B.P.; Hazarika, H.; Bharadwaj, R.; Loying, P.; Baishya, R.; Dash, S.; Das, M.K. Curcumin-docetaxel co-loaded nanosuspension for enhanced anti-breast cancer activity. Expert Opin. Drug Deliv. 2016, 13, 1065-1074. [CrossRef] [PubMed]

9. Motevalli, S.M.; Eltahan, A.S.; Liu, L.; Magrini, A.; Rosato, N.; Guo, W.; Bottini, M.; Liang, X.-J. Co-encapsulation of curcumin and doxorubicin in albumin nanoparticles blocks the adaptive treatment tolerance of cancer cells. Biophys. Rep. 2019, 5, 19-30. [CrossRef]

10. Li, X.; Yuan, H.; Zhang, C.; Chen, W.; Cheng, W.; Chen, X.; Ye, X. Preparation and in-vitro/in-vivo evaluation of curcumin nanosuspension with solubility enhancement. J. Pharm. Pharmacol. 2016, 68, 980-988. [CrossRef]

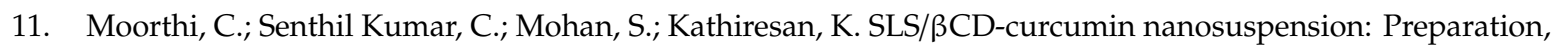
characterization and pharmacological evaluation. J. Pharm. Res. 2013, 7, 219-223. [CrossRef]

12. Mai, H.; Nguyen, T.; Le, T.; Nguyen, D.; Bach, L. Evaluation of Conditions Affecting Properties of Gac (Momordica Cocochinensis Spreng) Oil-Loaded Solid Lipid Nanoparticles (SLNs) Synthesized Using High-Speed Homogenization Process. Processes 2019, 7, 90. [CrossRef]

13. Mai, H.C.; Le, T.T.T.; Diep, T.T.; Le, T.H.N.; Nguyen, D.T.; Bach, L.G. Development of Solid Lipid Nanoparticles of Gac (Momordica cocochinensis Spreng) Oil by Nano-Emulsion Technique. Asian J. Chem. 2018, 30, $293-297$. [CrossRef] 
14. Nhan, N.P.T.; Hien, T.T.; Nhan, L.T.H.; Anh, P.N.Q.; Huy, L.T.; Nguyen, T.C.T.; Nguyen, D.T.; Bach, L.G. Application of Response Surface Methodology to Optimize the Process of Saponification Reaction from Coconut Oil in Ben Tre-Vietnam. Solid State Phenom. 2018, 279, 235-239. [CrossRef]

15. Abbas, S.; Bashari, M.; Akhtar, W.; Li, W.W.; Zhang, X. Process optimization of ultrasound-assisted curcumin nanoemulsions stabilized by OSA-modified starch. Ultrason. Sonochem. 2014, 21, 1265-1274. [CrossRef]

16. Homayouni, A.; Amini, M.; Sohrabi, M.; Varshosaz, J.; Nokhodchi, A. Curcumin nanoparticles containing poloxamer or soluplus tailored by high pressure homogenization using antisolvent crystallization. Int. J. Pharm. 2019, 562, 124-134. [CrossRef]

17. Bach, L.T.; Hue, B.T.B.; Tram, N.T.T.; Thu, D.N.A.; Dung, L.T. Chemical constituents from $n$-hexane and ethyl acetate extracts of Euphorbia hirta L. grown in Vietnam. IOP Conf. Ser. Mater. Sci. Eng. 2020, 736, 022083. [CrossRef]

18. Nguyen, M.T.; Nguyen, V.T.; Minh, L.V.; Trieu, L.H.; Cang, M.H.; Bui, L.B.; Le, X.T.; Danh, V.T. Determination of the phytochemical screening, total polyphenols, flavonoids content, and antioxidant activity of soursop leaves (Annona muricata Linn.). IOP Conf. Ser. Mater. Sci. Eng. 2020, 736, 062011. [CrossRef]

19. Nguyen, N.Q.; Minh, L.V.; Trieu, L.H.; Bui, L.M.; Lam, T.D.; Hieu, V.Q.; Khang, T.V.; Trung, L.N.Y. Evaluation of total polyphenol content, total flavonoid content, and antioxidant activity of Plectranthus amboinicus leaves. IOP Conf. Ser. Mater. Sci. Eng. 2020, 736, 062017. [CrossRef]

20. Trinh, P.T.N.; Nguyen, T.Q.; Hau, N.V.; Hung, Q.T.; Du, C.V.; Tuan, N.T.; Thuy, N.T.L.; Dung, L.T. Chemical constituents of the stem of Coccinia grandis. IOP Conf. Ser. Mater. Sci. Eng. 2020, 736, 022080. [CrossRef]

21. Thuong Nhan, N.P.; Tan Thanh, V.; Huynh Cang, M.; Lam, T.D.; Cam Huong, N.; Hong Nhan, L.T.; Thanh Truc, T.; Tran, Q.T.; Bach, L.G. Microencapsulation of Lemongrass (Cymbopogon citratus) Essential Oil Via Spray Drying: Effects of Feed Emulsion Parameters. Processes 2020, 8, 40. [CrossRef]

22. Phan, A.N.Q.; Bach, L.G.; Nguyen, T.D.; Le, N.T.H. Efficient Method for Preparation of Rutin Nanosuspension Using Chitosan and Sodium Tripolyphosphate Crosslinker. J. Nanosci. Nanotechnol. 2019, 19, 974-978. [CrossRef]

23. Minh, N.P.; Bach, L.G.; Loan, L.Y.; Tram, V.T.B.; Van Truyen, T. Production of dried tea from okra (Abelmoschus Esculentus). J. Pharm. Sci. Res. 2019, 11, 279-283. Available online: https://www.jpsr.pharmainfo.in/ Documents/Volumes/vol11issue02/jpsr11021903.pdf (accessed on 1 June 2020).

(C) 2020 by the authors. Licensee MDPI, Basel, Switzerland. This article is an open access article distributed under the terms and conditions of the Creative Commons Attribution (CC BY) license (http://creativecommons.org/licenses/by/4.0/). 